\title{
Testing for Shift-Contagion Vulnerability Among MENA Stock Markets During the Turkish Financial Crisis
}

\author{
Osama M Badr ${ }^{1} \&$ Wajih Khallouli \\ ${ }^{1}$ Faculty of Commerce, Tanta University, Egypt \\ ${ }^{2}$ College of Islamic Economics and Finance, Department of Banking and Financial Markets, Umm Al-Qura University, \\ Mecca 21955, Saudi Arabia \\ Correspondence: Osama M Badr, Faculty of Commerce, Tanta University, Egypt.
}

Received: October 22, 2018

Accepted: November 26, 2018 Available online: December 6, 2018

doi:10.11114/aef.v6i1.3704

URL: https://doi.org/10.11114/aef.v6i1.3704

\begin{abstract}
This paper is an empirical study that seeks to determine whether any of the Middle East and North Africa (MENA) stock markets are vulnerable to financial contagion in the wake of the 2001 Turkish crisis. We test the nonlinearity of the mechanisms spreading shocks, estimated with a model of long-term interdependence. Our results provide evidence of a high level of interdependence between MENA stock markets. However, we find that, with the exception of the contamination of Israel's stock market, there is no longer evidence of shift-contagion in the transmission of financial shocks across MENA stock markets.
\end{abstract}

Keywords: shift-contagion, Middle East and North Africa, non-linear error, correction model

JEL classification: C32; F31; G15

\section{Introduction}

During the past decade, the financial liberalization policies adopted by the developed economies in the Middle East and North Africa (MENA) have increased integration between the international financial markets of the region. Several studies have suggested that increasing global integration is beneficial to growth and employment (Collins and Abrahamson, 2006). Other studies showed that the high integration among international financial markets generally increases the interdependence between them. Hence, present MENA stock markets display opportunities for international diversification (Bekaert and Harvey, 2003; Lagoarde-Segot and Lucey, 2007). On the other hand, the downside to high integration is an increased sensitivity to capital flows and an increased exposure to the transmission of the negative shocks; the more integrated markets are more vulnerable to the effects of a shock in another country. In fact, for Colins and Biekpe (2003), the spread of a crisis depends heavily on the degree of financial market integration since the international investors are actively investing in the afflicted markets. The transmission of the shocks results from financial panics and herding or switches of expectations of multiple equilibria (equilibrium with speculative attacks vs. equilibrium without speculative attacks) (Masson 1999). This phenomenon has often been described as contagion (Forbes and Rigobon, 2002). To explain this phenomenon, Park and Song (2001) suppose that if the financial markets of the countries in the region are tightly integrated then market participants will expect to see co-movements in financial asset prices in those markets. This condition may give rise to the contagion of a shock. For Goldstein and Pauzner (2004), a large decline in equity prices in one country may result in a large capital loss to the international investors who diversify their portfolios. This may induce these investors to rebalance their portfolios for a preoccupation of risk or a liquidity management (escape towards quality). This shift in the behaviour of investors consists in a shift in their expectations. Forbes and Rigobon (2001) refer to crisiscontingent theories and give this phenomenon the name "shift-contagion". The authors assume that investors behave differently after a crisis, implying a generation of the new temporary channels of propagation in addition to the permanent channels which characterize the interdependence between the economies. Empirically, the generation of new temporary channels corresponds to a nonlinearity characterizing both the asymmetric equilibria of stability and the crisis of the contaminated economy. By contrast, in non-crisis-contingent theories, there is no difference in the transmission mechanisms between both crises and stable periods. Along the same lines, the shocks are propagated through strong linkages between countries, such as trade links (Gerlach and Smets, 1995; Corsetti et al., 1999), financial links (Kaminsky and Reinhart, 2000; Van Rijckeghem and Weder, 2003) or common shocks (Masson, 1999; Forbes and Rigobon, 2001). 
Forbes and Rigobon (2002) used the term interdependence to refer to this situation.

The objective of this paper is to investigate this issue in the context of the MENA region. Indeed, contagion vulnerability in the MENA region has received fairly little interest despite the significant equity market change in the region since the 1990s. Table 1 shows the major MENA stock markets development in terms of sizes, maturity and capitalization. Hence, the study determines whether any MENA market, which seems start to integrate emerging markets, is vulnerable to financial contagion during the Turkish crisis of 2001.

Table 1. Comparative indicators for MENA financial markets (2003)

\begin{tabular}{lccc}
\hline Country & $\begin{array}{l}\text { Market } \\
\text { capitalization/GDP (\%) }\end{array}$ & Liquidity $(\%)^{\mathrm{b}}$ & Listed companies $^{\mathrm{c}}$ \\
\hline Egypt & 33.79 & 15.61 & 967 \\
Morocco & 29.32 & 18.72 & 52 \\
Tunisia & 10.03 & 7.73 & 45 \\
Jordan & 110.73 & 23.78 & 161 \\
Lebanon & 7.91 & 8.72 & 14 \\
Israel & 67.23 & 27.74 & 577 \\
Turkey & 29.36 & 143.55 & 285 \\
\hline
\end{tabular}

Source: Lagoarde-Segot and Lucey (2007)

a Market capitalization/GDP' is the market capitalization at the end of each year divided by GDP for the year

b 'Liquidity' corresponds to total value traded for the year divided by market capitalization.

c 'Listed companies' are the number of listed companies at the end of the year.

Although these countries are less financially integrated because of capital controls or a lack of access to international financing, Lagoarde-Segot and Lucey (2009) suggest that contagion may be caused by the cognitive convergence of domestic investors during the global financial turmoil. This study's aim is, thus, to estimate a model for financial interdependence and to detect nonlinearity in the international propagation of shocks among the MENA countries. For this purpose, it uses the Escribano-Pfann (1998) approach in order to test the nonlinearity of the mechanisms for spreading shocks, estimated with a model of interdependence. Its test for the presence of shift-contagion thus proceeds in two stages: In the first one, it tests the possibility of the presence of a co-integration relationship between the stock markets. Such a relationship shows the existence of the permanent channels through which the shocks are normally transmitted. In the second stage, it tests the assumption according to which these channels were modified during the period of crisis. In other words, the study tests nonlinearity in the behaviour of short-run adjustment which leads to long-run equilibrium in an Error Correction Model (ECM) using the Escribano-Pfann (1998) approach. Using some of the daily indices of the MENA stock market as measurements of the risk aversion of investors to risk premium, this research shows some results related to the identification of the shift-contagion in the MENA stock market during the Turkish crisis.

The remainder of the paper is organized as follows: Section 2 recalls different measurements of the shift-contagion and their limits. Section 3 outlines the methodology followed. Section 4 presents the data and the obtained empirical results. Section 5 concludes the paper.

\section{Shift-contagion Measurements}

In order to identify a possible shift-contagion, several methodologies were then used to test for the nonlinearity of the structural shocks (Favero and Giavezzi, 2002; Wälti, 2003; Bonfiglioli and Favero, 2005) or to investigate changes in the existence and directions of causality between the financial markets before and after the crisis (Masih and Masih, 1999; Sander and Kleimeir, 2003; AuYong et al., 2004). However, there are extensive empirical studies investigating the stability of the international propagation of financial shocks by a correlation analysis. In the empirical literature, shift-contagion is measured by a significant increase in the degree of the cross-markets financial links (approximated by the correlation) between tranquil and crisis periods (Baig and Goldfajn, 1998; Forbes and Rigobon, 2002; Rigobon, 2003). The pioneers who used this methodology to test for the presence of the contagion are King and Wadhwani (1990). They found that correlation between the United States, the United Kingdom and Japan's stocks markets had increased after the U.S. crash of 1987. However, tests based on an analysis of conditional correlation admit to several limits. The use of high frequency financial series affects the test through three types of bias: heteroskedasticity, simultaneous equations and omitted variables (Ronn, 1998; Forbes and Rigobon, 2002; Rigobon, 2003; and Yoon, 2005). In order to correct these problems, a structural change test (determinant of the change in the covariance matrix test) to test a structural break in the correlation across financial markets was proposed by Rigobon (2003). His results showed that the increase in the correlation between these stock markets did not result from instability in the mechanisms of propagation during recent international financial crises (Mexico 1994, Asia 1997 and Russia 1998), but was rather the consequence of a strong interdependence during the crisis period as well as during periods of the stability. Recently, Jokipii and Lucey (2007) used the DCC test for the banking contagion context. They examined the stability of the banking sector co-movements between the three largest 
Central and Eastern European Countries (CEECs) over the last decade and found evidence of the contagion from the Czech Republic to Hungary. All other market co-movements were attributed to interdependence. Most recently, LagoardeSegot and Lucy (2009) used a battery of bivariate contagion tests based on the correlation approach and found evidence that the MENA markets suffer more and more from contagion of the major crises in the last decades. In particular, their results suggested that the probability of being affected by contagion seems to increase for Israel and Turkey because they are the most developed markets in the MENA region in term of size and liquidity, and become more integrated in the world's markets. Although the conclusions of the contagion test based on correlation were interesting, the results were not considered robust. Indeed, the size of the crisis window had an important influence on the sensitivity of the results (see Billio and Pelizzon, 2003; and Dungey and Zhumabekova, 2001).

In order to solve this problem of crisis window definition, Caporale et al. (2005) tested for the stability of the propagation mechanisms using an approach based on an estimate of the full sample. They corrected the heteroskedasticity, assuming that the structural shocks following a GARCH $(1,1)$ process. Their results suggest the existence of the contagion between the Asian stocks markets. Using the same approach, McAleer and Wei Nam (2005) also verified the contagion between the Asian foreign exchange markets. In contrast to Rigobon (2003), other studies tested for the stability of the propagation mechanisms using the full-information estimation (Favero and Giavazzi, 2000, 2002; Wälti, 2003; and Bonfiglioli and Favero, 2005). Indeed, Favero and Giavazzi (2002) showed that this approach provided a more powerful test. Wälti (2003) introduced a proxy variable for the international common shocks (Monsoonal Effect), and found that the null hypothesis of the stability of propagation mechanisms between Asian stock markets is largely rejected. To solve the problem of the crisis window definition, Gravelle et al. (2006) developed a method for detecting shift-contagion using a bivariate regimeswitching model in which common shocks move between low- and high-volatility states. They tested the null assumption of the absence of contagion according to which the propagation mechanisms of the idiosyncratic shocks does not change even when major a common shock occurs. Formally, shift-contagion is identified when the ratio of the impact coefficients for the common shocks of the two countries will be different during crises than in normal periods. In fact, this change is due to the increase in the interdependence between these two countries over time. Gravelle at al. (2006) applied their method to currency markets for some developed countries and bond markets for Latin American countries. Their results suggested the presence of shift-contagion for European countries, and confirmed the results of Rigobon (2003) concerning the little evidence of shift-contagion in Latin American countries. Flavin and Panopoulou (2006) employed the methodology of Gravelle et al. (2006) between pairs of East Asian equity markets to identify shift-contagion caused by the 1990's financial crisis. They found little evidence of the presence of contagion between the financial East Asian markets.

Despite the importance of all these methods that permit the testing of shift-contagion in the presence of interdependence, they don't discriminate between short-run and long-run interdependence. Cashin et al. (1995) analysed the contagion effect using the error correction model for some integrated stock markets with similar behaviour in the long run. Tan (1998) proposed an alternative approach to assessing the extent of contagion. He tested co-integration between crosscountry stock prices and specified the Vector Error Correction Model (VECM) to capture short-term effects that may be conveyed by fundamentals and herding behaviour contagion. Therefore, the author distinguished between the fundamental contagion captured by the error correction term, and the shift-contagion captured by the first differenced components of the VECM. He confirmed the contagion effect during the Asian financial crisis. Bonfiglioli and Favero (2005) distinguished also between long-run and short-run dynamics for interdependence. In line with Favero and Giavazzi (2002), they verified the instability of the propagation mechanisms between the United States and Germany's stock markets using a Vector Error Correction Model. They found existence of the long-run interdependence and nonlinearity of the idiosyncratic shocks between the two markets. Recently, Ayadi et al. (2006) proposed a new methodology for testing the nonlinearity of the spreading shocks' mechanisms among five Asian sovereign debt (spreads) markets. In line with Tan (1998), they considered that the error correction term captures the fundamental contagion that represents the permanent transmission mechanisms according to non-crisis-contingent theories of Forbes and Rigobon (2001). Therefore, to identify shift-contagion, these authors tested only the nonlinearity of the error correction term in the error correction model. Their results prove that Malaysia and the Philippines were contaminated by contagion during the financial Asian crisis. In this paper, the methodology of Ayadi et al. (2006) is used for testing shift contagion. Contrary to previous research, this procedure enables the authors to solve the problem of crisis window definition by using the totality of the period in their estimation. The paper is interested in analysing the vulnerability of the MENA stock markets to the shiftcontagion.

\section{Methodology}

Like Rigobon (2003), this work defines shift-contagion as the rise in cross-market interdependency after a shock caused by one or more countries. The rise in interdependency must be associated with a nonlinearity that shows the generation of the new transmission mechanisms of the shocks among countries (Favero and Giavazzi, 2002). Those new mechanisms did not exist during the tranquil period. Indeed, they reflect the switching in the investors' expectations. This paper 
distinguishes between long-run and short-run interdependence for different markets. Indeed, the long-run interdependence is generated by a situation of integration between the financial markets. Shift-contagion is then identified via a model of long-run interdependence represented by a co-integrated system. Hence, it is necessary to estimate the structural financial interdependence model ${ }^{1}$ that has an untraceable form. To achieve this purpose, a reduced form of ECM specification is used. Indeed, if two time series $x_{t}$ and $y_{t}$ are nonstationary, integrated of the same order and their linear combination $z_{t}^{2}$ is already stationary, the two series are said to be co-integrated (Engel and Granger, 1987). Thus, an ECM is estimated that represents the short-run dynamics and which maintains the long-run equilibrium between the two series:

$$
\Delta y_{t}=\sum_{i=1}^{p} \theta_{i} \Delta y_{t-i}+\sum_{i=1}^{q} \lambda_{i} \Delta x_{t-i}+\delta z_{t-1}+\varepsilon_{t}
$$

where $\varepsilon_{t}$ is the error terms assumed to be independent and independently distributed with zero mean and unit variance. $z_{t-1}$ is the error correction term. $\delta$ is the adjustment speed parameter, measuring the error-correction mechanism that drives the $y_{t}$ back to their long-run equilibrium relationship.

For Forbes and Rigobon (2001), the linear co-integration relation shows the existence of the permanent channels of the shocks propagation between the financial markets. Indeed, as with Tan (1998), this study considers that the error correction term may be the appropriate representation of these permanent channels. In the structural form of the financial interdependence model, these channels are represented by the parameter $\beta$ of the long-run equilibrium equation. In line with Bonfiglioli and Favero (2005), this parameter, that describes the long-run equilibria, represents the long-run interdependence. Also, note that the coefficients $\theta_{i}$ and $\lambda_{i}$ in equation (1) capture the short-run responses of the domestic stock indices due to changes in lagged values of the domestic and other countries' stock markets. The issue represents short-run interdependence. For Tan (1998), it may represent herding behaviour of investors.

In order to identify the shift-contagion, the study extends its analysis by testing the nonlinearity of the permanent channels of the shocks propagation from $x_{t}$ to $y_{t}$, according to Favero and Giavazzi (2002). For this, the study tests the nonlinearity of the interdependence model by testing nonlinearity in the behaviour of short-run adjustment which leads to long-run equilibrium using the Escribano-Pfann (1998) approach. This work therefore uses the Non-linear Error Correction (NEC) model in which the linear error correction term $z_{t-1}$ is replaced by the asymmetric term. To measure the asymmetric error correction it introduces the following concepts as Escribano-Pfann (1998):

Positive error correction movements are characterized by positive differences between two subsequent measurement points of the long-run equilibrium error

$$
z_{t-1}^{+}= \begin{cases}z_{t-1} & \text { if } \Delta z_{t-1}>0 \\ 0 & \text { otherwise }\end{cases}
$$

Negative error correction movements are characterized by negative differences between two subsequent measurement points of the long-run equilibrium error

$$
z_{t-1}^{-}=\left\{\begin{array}{lr}
z_{t-1} & \text { if } \Delta z_{t-1}<0 \\
0 & \text { otherwise }
\end{array}\right.
$$

This transformation allows the creation of two equilibria each characterized by a specific adjustment speed. The first equilibrium is reflective of the tranquillity period and it is captured by the $z_{t-1}^{-}$term. On the other hand, the crisis equilibrium is captured by the $z_{t-1}^{+}$term. If $z_{t-1}$ is equal to zero, the propagation mechanisms are approximated by the ratio of the variations of two series $\left(\Delta z_{t-1}=0 \Leftrightarrow \beta=\frac{\Delta y_{t-1}}{\Delta x_{t-1}}\right)$. In fact, this ratio represents the short-run dynamics (comovements) which ensure the permanent propagation of the shocks between the two financial markets $x_{t}$ and $y_{t}$. During

\footnotetext{
1 See Forbes and Rigobon (2002) and Bonfiglioli and Favero (2005) for the structural model featuring a constant interdependence across countries required for estimating the international propagation mechanisms of shocks.

${ }^{2} z_{t}$ is the residual of the log-run equilibrium equation $\left(y_{t}=\hat{\alpha}+\hat{\beta} x_{t}+z_{\mathrm{t}}\right)$.
} 
the stability period, these co-movements prove to be lower than a level $\beta\left(\Delta z_{t-1}<0 \Leftrightarrow \frac{\Delta y_{t-1}<\beta}{\Delta x_{t-1}}\right)$. $\mathrm{Ho}_{\mathrm{Wever}}$, it becomes higher than this level $\beta$ during the crisis period $\left(\Delta z_{t-1}>0 \Leftrightarrow \frac{\Delta y_{t-1}}{\Delta x_{t-1}}>\beta\right)$. As a consequence, it is noted that if the ECM is nonlinear, the behaviour of the propagation mechanisms captured by the parameter $\beta$ changes during the crisis period since this work distinguishes a significant increase in the degree of the co-movements between the financial markets. Thus, the nonlinearity of the ECM shows a significant rise in cross-market interdependency after a shock. It then shows the existence of shift-contagion. Of course, with linear ECM, there would be no change in the interdependence between the two stock markets over the complete sample. Therefore, there would be no shift-contagion, by definition. On the other hand, in the presence of the nonlinearity in the co-movements, there can be change in the interdependence between stock markets. Hence, the new representation of the ECM with asymmetric adjustments is:

$$
\Delta y_{t}=\sum_{i=1}^{p} \theta_{i} \Delta y_{t-i}+\sum_{i=1}^{q} \lambda_{i} \Delta x_{t-i}+\delta_{1} z_{t-1}^{-}+\delta_{2} z_{t-1}^{+}+\varepsilon_{t}
$$

In line with Escribano-Pfann (1998), the hypothesis of linearity of ECM is rejected if $\delta 1$ is significantly different from $\delta 2$. This work confirms the existence of nonlinear error correction mechanisms, and then interprets this result by the existence of the shift-contagion that propagated from $x_{t}$ towards $y_{t}$. Finally, note that to correct the heteroskedasticity problem, the errors $\varepsilon_{t}$ are assumed to follow a GARCH $(1,1)$ process.

\section{Data and Empirical Results}

Following Tan (1998), Masih and Masih (1999), Baur (2003), and Rigobon (2003), weekly closing stock market index prices from five MENA countries are examined in this study: Egypt (EGY), Israel (ISR), Jordan (JOR), Morocco (MOR) and Turkey (TUR). The study chooses a log-transformation of the data in order to interpret the links between variables in terms of elasticity. All indices are denominated in US dollars. This allows this work to undertake the point of view of the international investors. The data are sampled over the period from January 2, 1998 to December 27, 2002 (yielding 261 observations), and obtained from the MSCI database. The use of weekly data is preferred, in order to avoid the problems of non-synchronous trading across markets. The sample period contained the crisis windows started in November 2000 with a rapid capital outflow from Turkish financial markets 3(Akyüz and Boratav, 2003). Table 2 provides the crossmarket correlations and some descriptive statistics for all of the countries analyzed.

Table 2. Correlations and descriptive statistics

\begin{tabular}{|c|c|c|c|c|c|}
\hline & EGY & ISR & JOR & MOR & TUR \\
\hline EGY & 1.000000 & & & & \\
\hline ISR & 0.921309 & 1.000000 & & & \\
\hline JOR & 0.068862 & 0.109875 & 1.000000 & & \\
\hline MOR & 0.220470 & 0.027125 & -0.730839 & 1.000000 & \\
\hline TUR & 0.631845 & 0.399264 & -0.275422 & 0.739722 & 1.000000 \\
\hline
\end{tabular}

This study begins its cointegration analysis by applying the unit root tests for all series of its sample. In addition to the Augmented Dickey Fuller (ADF) test, it also uses the Phillips Perron (PP) test, which takes into account in a nonparametric way both the autocorrelations and heteroskedasticity bias. Table 3 provides the results of the two unit root tests on levels and first differences of logs from all series. The tests reveal that all series are integrated of order one (I(1)) at $5 \%$ level. As such, it is possible that some combinations of them are co-integrated. This work therefore uses the Johansen's approach to test this possibility.

${ }^{3}$ February 2001 is the date of the Turkish financial crisis and the flotation of the Turkish lira. 
Table 3. Results of ADF and PP tests for Unit root on levels and first differences of logs of MENA stock market indices

\begin{tabular}{llclc}
\hline \multirow{2}{*}{ Stock indices } & \multicolumn{2}{c}{ Levels } & ADF & Pirst differences \\
\cline { 2 - 4 } & ADF & PP & -15.43 \\
EGY & -0.389 & -0.471 & -6.589 & -14.729 \\
ISR & -0.019 & -0.021 & -6.289 & -17.913 \\
JOR & -2.046 & -1.908 & -6.205 & -15.736 \\
MOR & -1.186 & -1.119 & -6.289 & -17.57 \\
TUR & -1.603 & -1.538 & \\
\hline
\end{tabular}

The critical values for ADF and PP tests are equal to (-2.87) at the 5\% level (source: Kwiatkowski et al., 1992).

Table 4 shows the results of the trace tests which provide the maximum number of cointegration relationships. As shown, the null hypothesis of absence of cointegration is rejected. On the other hand, this work accepts the null hypothesis of existence of at most only one cointegration relationship between the selected stock indices. Thus, Johansen's test shows that a single cointegrating vector exist without indicating the cointegrated variables. Indeed, the value of the trace test and Eigenvalue test are significant at the 5\% level. Nevertheless, the evidence of cointegration between MENA stock markets is consistent with the existence of high long-run interdependence between them. The result is similar to those obtained by Darrat et al. (2000) and Marashdeh (2005) which reveal the existence of the cointegration relation between some MENA stock markets. This result is quite admissible since the countries of the current work's sample are the most advanced markets in the MENA region in terms of size and foreign participation. Thus, it appears that there are permanent channels which assure the international propagation of financial shocks among these countries.

Table 4. Johansen's multivariate cointegration tests using trace statistic

\begin{tabular}{ccccc}
\hline Hypothesized & & Trace & 5 Percent & 1 Percent \\
\hline No. of CE $(\mathrm{s})$ & Eigenvalue & Statistic & Critical Value & Critical Value \\
\hline None $* *$ & 0.115911 & 76.84179 & 68.52 & 76.07 \\
\hline At most 1 & 0.080419 & 45.30309 & 47.21 & 54.46 \\
\hline At most 2 & 0.056332 & 23.84069 & 29.68 & 35.65 \\
\hline At most 3 & 0.030013 & 8.997663 & 15.41 & 20.04 \\
\hline At most 4 & 0.004664 & 1.196747 & 3.76 & 6.65 \\
\hline$* *)$ denotes rejection of the hypothesis at the 5\%(1\%) level & &
\end{tabular}

Trace test indicates 1 cointegrating equation(s) at both $5 \%$ and $1 \%$ levels

The critical values are given by Osterwald-Lenum (1992).

As shown before, in the presence of cointegration, there always exist a corresponding ECM which represents the comovements between stock indices and the possibility that they will trend together in establishing a long-run equilibrium or a long-run interdependence. Indeed, ECM estimates the propagation mechanisms of shocks (captured by errorcorrection term) from independent or explanatory stock indices (xt in equation 1)4 to the dependent stock indices (yt in equation 1). To control the heteroskedasticity problem identified by the ARCH test, this study estimates the ECM equations with GARCH $(1,1)$ process. The estimations using the maximum-likelihood method are thus reported in Table 5 .

${ }^{4} x_{t}$ is supposed to be at the origin of the shocks. It can represent several countries. In fact, this study does not limit itself to only one country as a source of contagion since it supposes that shocks can to be caused by one or more countries. However yt does not include Turkey because it is considered as the ' ground zero country' during the Turkish crisis. 
Table 5. Results of estimation of different linear ECM equations

\begin{tabular}{|c|c|c|c|c|}
\hline & $\Delta \mathrm{EGY}$ & $\Delta \mathrm{ISR}$ & $\triangle \mathrm{JOR}$ & $\triangle \mathrm{MOR}$ \\
\hline \multirow[t]{2}{*}{$\mathrm{C}$} & -0.006043 & -0.001464 & -0.000317 & -0.001342 \\
\hline & $\left(-3.494983^{* *}\right)$ & $(-0.984816)$ & $(-0.247867)$ & $(-0.489396)$ \\
\hline \multirow[t]{2}{*}{$\Delta \mathrm{EGY}(-1)$} & $0.036676(0.455051)$ & $0.025444(0.638268)$ & $0.005425(0.149069)$ & -0.137433 \\
\hline & $0.002647(0.038265)$ & 0.128680 & $0.080880(1.387877)$ & $(-1.761160)$ \\
\hline \multirow[t]{2}{*}{$\Delta \operatorname{ISR}(-1)$} & $0.082469(1.017391)$ & $\left(1.850725^{*}\right)$ & -0.092539 & -0.035764 \\
\hline & -0.030460 & -0.011043 & $(-1.468833)$ & $(-0.287665)$ \\
\hline \multirow[t]{2}{*}{$\Delta \mathrm{JOR}(-1)$} & $0.726274)$ & $(-0.176015)$ & $0.006106(0.195224)$ & -0.132307 \\
\hline & -0.006772 & -0.018166 & $0.012142(0.907575)$ & $(-0.976745)$ \\
\hline \multirow[t]{2}{*}{$\Delta \mathrm{MOR}(-1)$} & $(-0.543371)$ & $(-0.478337)$ & -0.047206 & $0.064296(0.953516)$ \\
\hline & -0.011202 & -0.000852 & $(-2.259463 * *)$ & $0.019430(0.668610)$ \\
\hline \multirow[t]{3}{*}{$\Delta \operatorname{TUR}(-1)$} & $(-1.010955)$ & $(-0.048962)$ & & -0.087736 \\
\hline & & -0.032120 & $7.396139(0.116377)$ & $(-2.993064 * *)$ \\
\hline & 31.26876 & $\left(-1.749778^{*}\right)$ & - & \\
\hline$z_{t-1}$ & $(0.000003 * *)$ & & & $0.948186(0.917548)$ \\
\hline \multirow[t]{2}{*}{ ARCH Test } & $2.212362(0.696767)$ & 9.165711 & & - \\
\hline & & $\left(0.057088^{* *}\right)$ & & \\
\hline$\chi_{A R C H}^{2}(\mathrm{p} \text {-value })^{\mathrm{a}}$ & & $4.379914(0.357025)$ & & \\
\hline$\chi_{A R C H}^{2}(\mathrm{p} \text {-value })^{\mathrm{b}}$ & & & & \\
\hline
\end{tabular}

The variables in top are the endogenous variables of equation 1 . Note that the lag length is arbitrarily determined.

The numbers in parentheses are t-statistics.

** Significance at the $5 \%$ level.

* Significance at the $10 \%$ level.

a Results of ARCH test after estimation without GARCH $(1,1)$ process.

$b$ Results of ARCH test after estimation with GARCH $(1,1)$ process.

In fact, since these ECM equations require normalization (choice of a dependant variable), the study reports estimations where it uses an endogenous variable for each equation. As shown, the coefficients associated with error-correction terms for all equations, except for the equation of which $\triangle \mathrm{EGY}$ is treated as the dependent variable, are significant at $5 \%$ or $10 \%$. Their signs are negative and conform to the economic intuition. Therefore, the adjustment towards the equilibrium phenomenon is verified, except in the case of Egypt. This outcome shows that any shock in the MENA region is compensated by a reaction of the Israel, Jordan and Morocco stock markets during the full period (before and after the Turkish crisis). This study thus verifies the existence of the permanent mechanisms of spreading shocks across MENA stock markets. It proposes to then examine the linearity of this interdependence using the asymmetric ECM. Indeed, it is the linearity test for adjustment towards the equilibrium which allows identifying shift-contagion from interdependence.

Table 6 reports results of the Fisher test for the nonlinearity of ECM equations and their estimations. Indeed, the estimated error correction parameters ( $\delta 1$ and $\delta 2$ in equation 2) provide useful additional information for two asymmetry adjustments between MENA stock markets towards stability equilibrium and Turkish crisis equilibrium by confirming the existence of the long-run cointegration relationship that represents the high long-run interdependence between these markets. As can be seen, for all equations, the coefficients associated with $z_{t-1}$ and $z_{t-1}$ have negative signs. It is in line with the expected error correction mechanisms. Thus, the condition of the adjustment back towards the two equilibria for the stability period and the turmoil period is verified. These results prove the existence of a permanent interdependence (permanent channels of the shocks transmission) between MENA stock markets, even those with a non-linear representation. However, this work rejected at $10 \%$ the hypothesis of linearity of ECM only for equations of which $\triangle \mathrm{ISR}$ is treated as the dependent variable: the p-value of the F-statistic testing the statistical significance of the asymmetry (Eq. 1) vs. the linear ECM model (Eq.2) yields p-value $=0.1$. It thus verifies the significant asymmetry of adjustment mechanisms towards stability equilibrium and crisis equilibrium for Israel's stock market only. However, the adjustment 
speed towards crisis equilibrium (0.06) exceeds the adjustment towards the stability equilibrium (0.0003). The nonlinearity detected implies changes in the propagation mechanisms of shocks between MENA countries. The shock transmission is especially present from Turkey -the "ground zero country"- to Israel. Indeed, these changes are generated by new propagation mechanisms arising, revealing the non-uniform risk perception of Israeli stock market investors. So, this study's results suggest that during the Turkish crisis, there was no evidence of shift contagion for any MENA market, with the exception of Israel, which is consistent with Lagoarde-Segot and Lucey's (2009) findings of the contamination of Israel's stock market during the 2001 Turkish crisis. These authors conclude also that the MENA markets are relatively immune. Their findings outline the important role played by Israel in the MENA region, in terms of financial integration of global capital flows. This implies that Israel is more heavily influenced by international investors. Following this, it is concluded that shift-contagion requires a higher participation of international investors and needs an advanced financial integration step in consequence.

Table 6. Results of estimation of different non- linear ECM equations

\begin{tabular}{|c|c|c|c|c|}
\hline & $\Delta \mathrm{EGY}$ & $\Delta \mathrm{ISR}$ & $\Delta \mathrm{JOR}$ & $\triangle \mathrm{MOR}$ \\
\hline \multirow[t]{2}{*}{$\mathrm{C}$} & -0.006037 & -0.001301 & $-8.67 \mathrm{E}-05$ & -0.001482 \\
\hline & $(-3.460743)$ & $(-0.860209)$ & $(-0.066463)$ & $(-0.531423)$ \\
\hline \multirow{2}{*}{$\Delta \mathrm{EGY}(-1)$} & 0.036493 & $0.022358(0.556977)$ & $0.006179(0.169721)$ & -0.137667 \\
\hline & $(0.449406)$ & & & $(-1.760856)$ \\
\hline$\Delta \mathrm{ISR}(-1)$ & $0.002638(0.038056)$ & $0.130727(1.843852 *)$ & $0.077100(1.319665)$ & \\
\hline \multirow[t]{2}{*}{$\Delta \mathrm{JOR}(-1)$} & 0.082424 & -0.008449 & -0.090360 & -0.031830 \\
\hline & $(1.015162)$ & $(-0.127995)$ & $(-1.432998)$ & $(-0.254056)$ \\
\hline \multirow[t]{2}{*}{$\Delta \mathrm{MOR}(-1)$} & -0.030762 & -0.026841 & $0.003185(0.101336)$ & -0.129570 \\
\hline & $(-0.731493)$ & $(-0.717119)$ & $0.012799(0.955205)$ & $(-0.952501)$ \\
\hline \multirow[t]{2}{*}{$\Delta \mathrm{TUR}(-1)$} & -0.006803 & 0.000575 & & 0.064665 \\
\hline & $(-0.544678)$ & $(0.032944)$ & & $(0.957075)$ \\
\hline \multirow{2}{*}{$z_{t-1}^{-}$} & -0.010525 & -0.000370 & -0.027999 & $0.019696(0.676215)$ \\
\hline & $(-0.694128)$ & $(-0.012816)$ & $(-0.961875)$ & \\
\hline \multirow{2}{*}{$z_{t-1}^{+}$} & -0.012298 & -0.060513 & -0.067370 & -0.096629 \\
\hline & $(-0.673435)$ & $\left(-2.579758^{* *}\right)$ & $\left(-2.259186^{* *}\right)$ & $(-2.277131 * *)$ \\
\hline \multicolumn{5}{|l|}{ ARCH Test } \\
\hline \multirow{2}{*}{$\chi_{A R C H}^{2}(\mathrm{p} \text {-value })^{\mathrm{a}}$} & $31.23308\left(0.000003^{* *}\right)$ & $8.552320\left(0.073317^{*}\right)$ & 6.871751 & -0.079900 \\
\hline & 2.236009 & $3.273330(0.513169)$ & $(0.142823)$ & $(-2.003340 * *)$ \\
\hline \multicolumn{5}{|l|}{$\chi_{A R C H}^{2}(\mathrm{p} \text {-value })^{\mathrm{b}}$} \\
\hline Linearity Test & $0.005070(0.943291)$ & $2.597948(0.108274 *)$ & $0.898380(0.344128)$ & $0.911961(0.922839)$ \\
\hline \multirow{2}{*}{$\left(\mathrm{H}_{0}: \delta_{1}=\delta_{2}\right)$} & & & & $0.084292(0.771803)$ \\
\hline & Accepted & Rejected & Accepted & Accepted \\
\hline \multicolumn{5}{|l|}{ F-statistics } \\
\hline \multicolumn{5}{|l|}{ (p-value) } \\
\hline Linearity Hypothesis & & & & \\
\hline
\end{tabular}

The variables in top are the endogenous variables of equation 1 . Note that the lag length is arbitrarily determined

The numbers in parentheses are t-statistics.

** Significance at the $5 \%$ level.

*Significance at the $10 \%$ level.

a Results of ARCH test after estimation without GARCH $(1,1)$ process.

b Results of ARCH test after estimation with GARCH $(1,1)$ process. 


\section{Conclusion and Policy Implications}

This paper is an attempt to investigate vulnerability to financial contagion in the context of emerging markets of the MENA region during the Turkish crisis in 2001. Following Ayadi et al. (2006), it tests shift-contagion by testing anonlinearity in the international propagation of shocks among a set of MENA stock market indices. Contrary to previous works, this study estimates a long-run interdependence model using cointegration analysis. It tests thereafter the nonlinearity of shocks propagation mechanisms in an ECM model that represents the short-term dynamics. Its methodology enables it to solve the problem of crisis window definition by using the totality of the period in its estimation.

Overall, its results highlighted that, with the exemption of the contamination of Israel, there is no evidence of significant change in the propagation mechanisms between MENA countries following the Turkish crisis. However, it finds that there is interdependence that generates permanent channels through which most financial shocks between the MENA stock markets are transmitted. These results have two important policy implications. First, given the existence of permanent channels of shocks' transmissions, the monetary authorities of MENA countries must reinforce their fundamentals, particularly their financial systems, in order to reduce the risk of permanent propagated regional shocks. Second, the study's empirical evidence of contagion in the MENA region is crucial to the MENA monetary authorities' decisions. It conditions the definition of measurements that can be adopted in order to avoid contagion and reduce vulnerability to external shocks. Indeed, the authorities may find it beneficial to adopt strategies of insulation in the short term so as to regulate the negative externalities of financial liberalisation.

\section{References}

Akyüz, Y., \& Boratav, K. (2003). The Making of the Turkisk financial crisis. World Development, 31(9), 1599-1566. https://doi.org/10.1016/S0305-750X(03)00108-6

AuYong, H. H., Gan, C., \& Treepongkaruna, S. (2004). Cointegration and causality in the Asian and emerging foreign exchange markets: Evidence from the 1990s financial crises. International Review of Financial Analysis, 13, 479515. https://doi.org/10.1016/j.irfa.2004.02.024

Ayadi, M., Boudhina, R., Khallouli, W., \& Sandretto, R. (2006). La contagion de la crise asiatique: dynamiques de court terme et de long terme. Economie Internationale, 105, 113-135.

Baig, T., \& Goldfajn, I. (1998). Financial market contagion in the asian crisis. IMF Working Paper, WP/98/155.

Baur, D. (2003). Testing for contagion - mean and volatility contagio. Journal of Multinational Financial Management, 13, 405-422. https://doi.org/10.1016/S1042-444X(03)00018-5

Bekaert, G., \& Harvey, G. R. (2003). Emerging markets finance. Journal of Empirical Finance, 10, 3-55. https://doi.org/10.1016/S0927-5398(02)00054-3

Billio, M., \& Pelizzon, L. (2003). Contagion and interdependence in stock markets: Have they been misdiagnosed? Journal of Economics and Business, 55, 405-426. https://doi.org/10.1016/S0148-6195(03)00048-1

Bonfiglioli, A., \& Favero, C. A. (2005). Explaining co-movements between stock markets : the case of US and Germany. Journal of International Money and Finance, 24(8), 1299-1316. https://doi.org/10.1016/j.jimonfin.2005.08.016

Caporale, G. M., Cipollini, A., \& Spagnolo, N. (2005). Testing for contagion: a conditional correlation analysis. Journal of Empirical Finance, 12, 476-489. https://doi.org/10.1016/j.jempfin.2004.02.005

Cashin, P., Kumar, M. S., \& McDermott, G. J. (1995). International integration of equity markets and contagion effects. IMF Working Paper, WP/95/110.

Collins, D., \& Biekpe, N. (2003). Contagion: a fear for African equity markets? Journal of Economics \& Business, 55(5), 405-426. https://doi.org/10.1016/S0148-6195(03)00020-1

Collins, D., \& Abrahamson, M. (2006). Measuring the cost of equity in African financial markets. Emerging Markets Review, 7, 67-81. https://doi.org/10.1016/j.ememar.2005.06.003

Corsetti, G., Pesenti, P., Roubini, N., \& Tille, C. (1999). Competitive devaluations: a welfare-based approach. NBER Working Paper Series, 6889.

Darrat, A. F., Elkhal, K., \& Hakim, S. R. (2000). On the Integration of Emerging stock markets in the Middle East. Journal of Economic Development, 25, 119-129.

Dungey, M., \& Zhumabekova, D. (2001). Testing for contagion using correlation: some words of caution. Pacific Basin Working Paper Series, n PB01-09.

Engle, R. F., \& Granger, C. W. J. (1987). Co-integration and error correction representation, estimation and testing. Econometrica, 55, 251-276. https://doi.org/10.2307/1913236 
Escribano, A., \& Pfann, A. G. (1998). Non-linear error correction, asymmetric adjustment and cointegration. Economic Modelling, 15, 197-216. https://doi.org/10.1016/S0264-9993(97)00023-0

Favero, C. A., \& Giavazzi, F. (2000). Looking for contagion: Evidence from the ERM. NBER Working Paper Series, 7797.

Favero, C. A., \& Giavazzi, F. (2002). Is the international propagation of financial shocks non-linear? Evidence from the ERM. Journal of International Economics, 57, 231-246. https://doi.org/10.1016/S0022-1996(01)00139-8

Flavin, T., \& Panopoulou E. (2006). Shift versus traditional contagion in Asian markets. IIS Discussion Paper n176, September.

Forbes, K., \& Rigobon, R. (2001). Contagion in Latin America: Definition, Measurement, and Policy Implications. MitSloan school of management and NBER, January 17.

Forbes, K., \& Rigobon, R. (2002). No contagion, only interdependence: Measuring stock market co-movements, Journal of Finance, 57(5), 2223-2261. https://doi.org/10.1111/0022-1082.00494

Gerlach, S., \& Smets, F. (1995). Contagious Speculative Attacks. European Journal of Political Economy, 11, 45-63. https://doi.org/10.1016/0176-2680(94)00055-O

Goldstein, I., \& Pauzner, A. (2004). Contagion of self-fulfilling financial crises due to diversification of investment portfolios. Journal of Economic Theory, 119, 151-183. https://doi.org/10.1016/j.jet.2004.03.004

Gravelle, T., Kichian, M., \& Morley, J. (2006). Detecting shift contagion in currency and bond markets. Journal of International Economics, 68, 409-423. https://doi.org/10.1016/j.jinteco.2005.07.005

Jokipii, T., \& Lucey, B. (2007). Contagion and interdependence: Measuring CEE banking sector co-movements. Economic Systems, 31, 71-96. https://doi.org/10.1016/j.ecosys.2006.05.001

Kaminsky, G., \& Reinhart, C. (2000). On crises, contagion and confusion». Journal of International Economics, 51, 145 168. https://doi.org/10.1016/S0022-1996(99)00040-9

King, M., \& Wadhwani, S. (1990). Transmission of volatility between stock markets. Review of Financial Studies, 3(1), 5-33. https://doi.org/10.1093/rfs/3.1.5

Lagoarde-segot, T., \& Lucey, B. M. (2007). International portfolio: is there a role for the Middle east and North Africa?. Journal of Multinational Financial Management, 17(5), 401- 410. https://doi.org/10.1016/j.mulfin.2007.01.001

Lagoarde-segot, T., \& Lucey, B. M. (2009). Shift-contagion vulnerability in the MENA stock markets. The World Economy, 32(10), 1478-1497. https://doi.org/10.1111/j.1467-9701.2009.01204.x

MacKinnon, J. (1991). Critical Values for Cointegration Tests, in Long-Run Economic Relationships. Engle R. \& Granger C. (ed.), Oxford University Press.

Marashdeh, H. (2005). Stock market integration in the MENA region: An application of the ARDL bounds testing approach, University of Wollongong. Economics Working Paper Series 05-27, November.

Masih, A. M. M., \& Masih, R. (1999). Are Asian stock market fluctuations due mainly to intra-regional contagion effects? Evidence based on Asian emerging stock markets». Pacific-Basin Finance Journal, 7, 251-282. https://doi.org/10.1016/S0927-538X(99)00013-X

Masson, P. R. (1999). Contagion: macroeconomic models with multiple equilibria. Journal of International Money and Finance, 18, 587-602. https://doi.org/10.1016/S0261-5606(99)00016-9

McAleer, M., \& Wei, N. J. C. (2005). Testing for contagion in ASEAN exchange rates. Mathematics and Computers in Simulation, 68, 519-527. https://doi.org/10.1016/j.matcom.2005.02.008

Park, Y. C., \& Song, C. Y. (2001). Institutional Investor, Trade Linkage, Macroeconomic Similarities, and Contagion of the Thai crisis. Journal of the Japanese and International Economies, 15, 199-224. https://doi.org/10.1006/jjie.2000.0464

Rigobon, R (2003). On the measurement of international propagation of shocks: is the transmission stable? Journal of International Economics, 61, 261-283. https://doi.org/10.1016/S0022-1996(03)00007-2

Ronn, E., Aking, S., \& Tompaidis, S. (1998). "The Impact of Large Changes in Asset Prices on Intra-Market Correlations in the Stock and Bond Markets".Working Paper, University of Texas at Austin.

Sander, H., \& Kleimeier, S. (2003). Contagion and causality: an empirical investigation of four Asian episodes. Journal of International Financial Markets, Institutions \& Money, 13, 171-186.

Tan, J. A. R. (1998). Contagion effects during the Asian financial crisis: Some evidence from stock price data. Pacific Basin Working Paper Series n 98-06. 
Van, R C., \& Weder, B. (2003). Spillovers through banking centers: a panel data analysis of bank flows. Journal of International Money and Finance, 22, 483-509. https://doi.org/10.1016/S0261-5606(03)00017-2

Wälti, S (2003). Testing for contagion in international financial markets: which way to go? HEI Working Paper 04/2003.

Yoon, G. (2005). Correlation Coefficients, Heteroskedasticity and Contagion of Financial Crises. Manchester School, 73(1), 92-100. https://doi.org/10.1111/j.1467-9957.2005.00426.x

\section{Copyrights}

Copyright for this article is retained by the author(s), with first publication rights granted to the journal.

This is an open-access article distributed under the terms and conditions of the Creative Commons Attribution license which permits unrestricted use, distribution, and reproduction in any medium, provided the original work is properly cited. 